\title{
The Future of the South African Retail Pharmacy Industry in the Light of Inter- national Experience and the Changing Healthcare Market $^{1}$
}

Martin Wessels

Business School, University of South Africa

John Luiz

Wits Business School, University of the Witwatersrand

\section{ABSTRACT}

The paper evaluates how the changing South African healthcare market is likely to affect the future of retail pharmacy. It examines current developments in retail pharmacy and the impact that these developments will have on the retail pharmacy market. This information is used to create scenarios as to what types of retail pharmacies are likely to thrive in the future.

JEL I1 1

\section{INTRODUCTION}

Retail pharmacy has been undergoing dramatic changes over the last decade. These changes seem to be rapidly increasing as more and more pressure is being exerted on retail pharmacy both externally and internally. The effect of these changes can be seen in the reduction in the number of retail pharmacies during the last decade and the change in the types of pharmacy that currently exist. This has left many pharmacy owners in a very precarious position as their businesses become less profitable while having to face increased competition and a dramatically changing environment. For retail pharmacy to survive it has to create value in the market place and it would appear that traditional pharmacies are not adding as much value as they once did. Thus the challenge for independent pharmacies is to gain a clear picture of the healthcare market, what it requires and how they can meet its needs.

The main purpose of the study is to consider where healthcare is moving in South Africa and assess how this is likely to affect the future of retail pharmacy. 
It examines current developments in retail pharmacy and the impact that these advances will have on this market.

\section{OVERVIEW OF THE SOUTH AFRICAN HEALTHCARE SECTOR}

South Africa has undergone significant social and political changes over the last decade and this has impacted the government's view of the healthcare market. The vision of the Department of Health is that all South Africans should have access to affordable, good quality healthcare. Traditionally the state has been responsible for providing healthcare to the poor who have conventionally been excluded from the private medical aid system mainly due to socio-economic reasons.

The public sector has been plagued with a lack of resources, which has lead to poor quality healthcare provision in many areas. The private sector has not been able to participate in the provision of public health on behalf of the state because the state has a closed ordering system that is not suitable for interaction with the private sector.

The potential for merging both the private and publics sector in some form has not escaped the attention of the government. Recently a commission of inquiry into a comprehensive system of social security released a report that recommends the introduction of a National Health Insurance (NHI) system that will fund both the public and private sector, over the next few years (Wolvaardt, 2002: 10). If implemented these changes could have a dramatic affect on the face of healthcare in South Africa (see Luiz, 1994).

The proposed report aims at dramatically increasing the number of people that belong to medical aids through legislation that will force middle and highincome earners to belong to medical schemes. For this to be practical, medical inflation will have to be brought in line with ordinary inflation. The report proposes to achieve this goal by doing the following (Wolvaardt, 2002: 10-11):

- Controlling the geographical distribution of services

- $\quad$ Licensing the introduction and distribution of new technology

- $\quad$ Restricting private hospital beds

- $\quad$ Removing all perverse incentives

- Directly controlling the price of goods and services

- Capping medical scheme administration fees

- $\quad$ Limiting annual medical schemes premium increases to ordinary inflation

- Controlling broker fees 
- Making public sector services available to medical schemes on a cost recovery basis

- $\quad$ Promoting managed healthcare

While this report has many positive aspects in that it will draw more people under the healthcare umbrella, it also carries with it many dangers (see Luiz \& Wessels, 2003 for a more detailed discussion).

The South African private sector accounts for 54 per cent of the total health care spend in South Africa and 3.8 per cent of the total GDP spent in 1998 (UNDP, 2001: 159). Of the total private health care bill of R30.23 billion, R26 billion is spent by medical aids. In 2001 the medical aid membership stood at just over 7 million. Thus in the private sector the medical aids have tremendous power in terms of the allocation of spending. However, they also realize that there are approximately 33 million people that are not covered by medical aids (Council for Medical Schemes, 2002: 27). This leaves a tremendous window of opportunity for medical aids to expand if they can create affordable products for this large untapped market. This is verified by a labour survey in 2001 that showed that in the main industries in South Africa only 29 per cent of employees contribute to a medical aid (SAIRR, 2001: 300).

The rapid rise in medical inflation has put enormous pressure on medical aids to contain costs and to keep their premiums affordable. Medical aids are being forced to look at new ways to contain costs such as pushing for managed health care $^{2}$. The basis of managed healthcare is that it begins with cost cutting measures such as demanding discounts and proceeds to its most advanced form with a transfer of risk from the medical aid to the health provider, and thus the provider becomes motivated to reduce costs. These challenges facing the medical schemes have, in turn, affected the retail pharmacy industry substantially, which is the topic of the next section.

\section{THE SOUTH AFRICAN RETAIL PHARMACY INDUSTRY}

Traditionally customers claimed directly from their medical aids and paid their pharmacy account when reimbursed. This resulted in pharmacies having a large number of accounts for customers. However, technological developments have allowed for direct claiming by pharmacies on behalf of their customers. As medicines advanced and their prices increased, pressure was put on the medical aids to contain costs. Medical aids began to demand discounts which put pressure on margins. Suddenly small pharmacies with low turnovers found they were no longer profitable and had to close. At the same time doctors, also 
feeling the pressure on their profits, began to dispense which added more competition in the market place.

During the 1990s the number of retail pharmacies declined significantly due to changing demographics, increased competition and declining margins. The advent of the big shopping malls drew people to regional centres which created the economies of scale that make the establishment of mega-stores possible. This has led to a huge growth in discount pharmacies that have developed into chains to increase their buying power. These discount pharmacies do not offer accounts and can therefore offer better prices, as their cash business leads to better cash flow. The discount pharmacy chains have aimed at reclaiming areas such as toiletries that had been lost to supermarkets and discount chain stores e.g. Clicks. In the process of attacking these other discount groups they have also put more pressure on the many smaller pharmacies that do not have the buying power to compete. Many of these smaller retail pharmacies were forced to close under this pressure. More recently there has been a move by independent retail pharmacists to open their pharmacies attached to large doctors' practices. This strategy seems successful because it offers convenience to the customer and allows small pharmacies to buy in bulk those items that the doctor practice prescribes. The only danger is that many medical aids are forming contracts with certain pharmacy groups, which may ultimately leave these independent pharmacies excluded. Since these pharmacies rely exclusively on prescription business this could be devastating to their business. South Africa currently has 2,693 retail pharmacies. This figure has begun to grow after a long decline. The most probable reason for the increase is the formation of small pharmacies located on the same premises as doctors and the opening of large discount pharmacies.

Before we can make any judgments about the retail pharmacy industry and those factors that impact on it we need to develop an understanding of the structure of the retail market. Porter's "five forces framework" (discussed in Grant, 1998: 55-65) relates the average profitability of participants in an industry to five competitive forces, namely:

- The degree of rivalry

- The threat of entry

- The threat of substitutes.

- Buyer power.

- Supplier power

The advantage of the five forces model is that it creates a picture of the entire industry and from this vantage point it is then much easier to make an informed decision as to what the industry might look like in the future. A five forces analysis of the retail pharmacy market is presented below. 


\section{Figure 2 The five forces model for the retail pharmacy market}

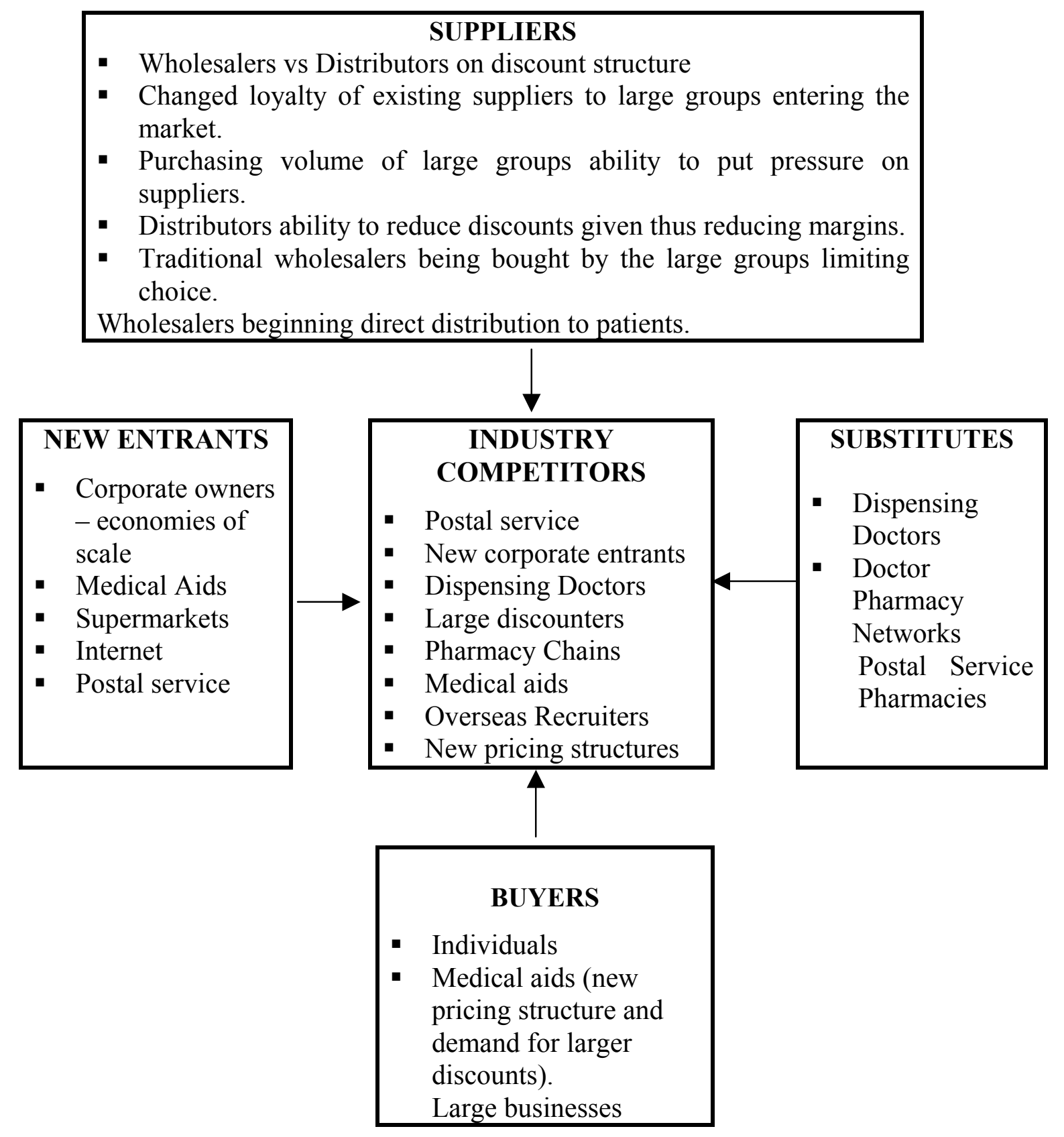

The above diagram attempts to illustrate the various forces that are acting on retail pharmacy and will probably have a big impact on the future of pharmacy. The main factors are discussed below.

\subsection{The new pricing structure}

The Pharmaceutical Society of South Africa (PSSA) has been working on a new pricing structure for medicines. The aim of this new pricing structure is to move pharmacists away from the current price plus mark-up system to one where pharmacists charge a professional fee. The idea is that this system would 
acknowledge the pharmacist's professional function in supervising medical utilization and disease prevention services for third party payers. This is to replace the current cycle of medical aids pressurizing for greater discounts in order to reduce their medicine costs. The current system encourages pharmacists to sell as much medicine as possible as their profit is directly related to turnover. The new professional fee will allow pharmacists to be paid for carrying out there professional functions and not as a mark-up per product sold. This means that if a pharmacist persuades a patient not to use medicine that may not be inappropriate the pharmacist will still be reimbursed this professional fee.

For medical aids this could also bode well as they will be paying a set fee per item. Pharmacists will be encouraged to use generics which are more cost effective as this will allow them to reduce the cost of their inventory. This will be a huge plus point for medical aids as generics cost on average a third of the original products price. What makes the new proposed pricing structure so controversial is that doctors will not be able to charge this fee. This means dispensing doctors will have to sell the medicine at cost. For these doctors dispensing has become a major source of their income which they are reluctant to give up.

\subsection{Corporate ownership}

The South African Pharmacy Act No 53 of 1974 Section 22A prohibits the ownership of retail pharmacy by non-pharmacists. This means that a retail pharmacy may not even have shareholders that are non-pharmacists. This has led to much debate as to whether this is in the best interest of the public. There is a belief by some that the law has essentially created a cartel and that this has led to higher prices for medicines than larger retailers, with their better distribution and management systems, could provide more affordably to the general public. A change in the law would also allow the medical aids to open their own pharmacies which would allow them to reduce their medicines bill. In recent years much pressure has been put on the government to have the Act amended to allow non-pharmacists to own retail pharmacies. Pharmacists have defended their right to ownership on the basis that medicines are not an ordinary commodity and that they require professional supervision. They claim that they play a major role in ensuring the correct usage of medicines and checking for possible drug interactions and that large corporates will only be interested in chasing profits to the detriment of patients and the pharmacy profession.

The table below hints at the relatively high cost of medicines in South Africa with pharmaceuticals making up a third of total health expenditure in the South African private sector which is three times that in the USA private sector. This is partly due to regulatory requirements which require pharmaceutical companies 
to supply the public sector at low tender rates which they then supplement by charging the private sector higher prices. In addition, it is claimed that the lack of free ownership of pharmacies which may hinder competition is a contributing factor to the cost of drugs.

Table 1 International comparisons of pharmaceutical expenditure as a proportion of total health expenditure

\begin{tabular}{|l|c|}
\hline \multicolumn{1}{|c|}{ Country Sector } & $\begin{array}{c}\text { Pharmaceutical expenditure as a } \\
\text { percentage of total health } \\
\text { expenditure }\end{array}$ \\
\hline UK National Health Service & $10.3 \%$ \\
USA & $8 . \%$ \\
SA private sector & $29 \%$ \\
SA public sector & $9.9 \%$ \\
SA weighted & $13.4 \%$ \\
\hline
\end{tabular}

Source: Melamet report, 1994

In many industrialised countries legislation was passed years ago which has allowed non-pharmacists to own pharmacies. In the US independent pharmacies have steadily gone down in numbers. Between 1985 and 1997, community pharmacies have declined by 14,341 while chain outlets increased to 18,229. By 1996 independent pharmacies were responsible for only 20.6 per cent of dollar prescription sales compared with 27.9 per cent for drug stores (Reekie, 1997: 279). With the large capital behind these corporate companies they have been able to form pharmacy chains which has given them large buying power and allows them to be very competitive. This put pressure on independent pharmacies which found it very difficult to compete resulting in a rapid decline in their numbers. Those that survived formed associations with other independent pharmacies so that they could compete by raising their volumes. In South Africa some of the large retail groups have also expressed interest in opening their own retail chains. The two chains that appear the most active at present are the New Clicks and Pick 'n Pay Groups.

\subsection{One exit price}

The government is very concerned with the high price of medication. One of their chief objectives is to try and make medicines affordable to the masses. For this reason they have proposed that there should be 'one exit price'. The intention is to create a transparent pricing system and thereby cut the fat out of 
the system. However, this will be very difficult to police and may ultimately not have the desired result.

The one exit price may lead to competition actually being stifled in that the larger players will no longer be able to put pressure on manufacturers to provide at reduced prices which can then be passed on to the consumer. The one exit price may ultimately end up protecting the small retail pharmacy by not allowing manufacturers to provide discounts where retailers may provide services that justify it. Pharmacists would like to see the end of discriminatory pricing between them and dispensing doctors. With doctors having the power to write prescriptions and therefore the power to influence the sales of prescription drugs they have traditionally been offered better prices in an attempt to lure them to prescribe the manufacturers drugs. This has obviously allowed for higher profit margins which makes prescribing these drugs very lucrative.

\subsection{Dispensing doctors}

With the advent of dispensing doctors in the last decade, pharmacists have lost a large proportion of the business that was traditionally theirs. In the early 1980s nearly all private sector sales passed through retail pharmacists. By 1993 this figure had fallen to 41.33 per cent by value with 42.89 per cent being paid out to dispensing doctors (Reekie, 1995: 112). This has lead to pharmacists having to offer additional services to generate revenue. These include blood pressure tests, cholesterol tests, and offering various consultations to patients. This has led to a blurring of the distinctions between these two professions. The table below outlines more recent developments in this regard.

The table shows that pharmacy's share have risen to 62 per cent although it could be misleading because part of this increase is due to postal service pharmacies which have taken business away from both retail pharmacies and dispensing doctors.

\subsection{Managed healthcare}

Retail pharmacy has been affected with the movement of medical aids into managed healthcare. Managed healthcare's aim of reducing the total bill for medicines has led to pharmacies experiencing shrinking turnover of medication on medical aids. They are introducing a host of different managed health tools aimed at reducing medicine utilization. These include evidence-based medicine which means that they will only pay for medicines that have been scientifically proven to be effective; and Pharmacy Benefit Management (PBM) organizations that review chronic utilization against standard protocol and recommend cheaper alternatives where possible. 


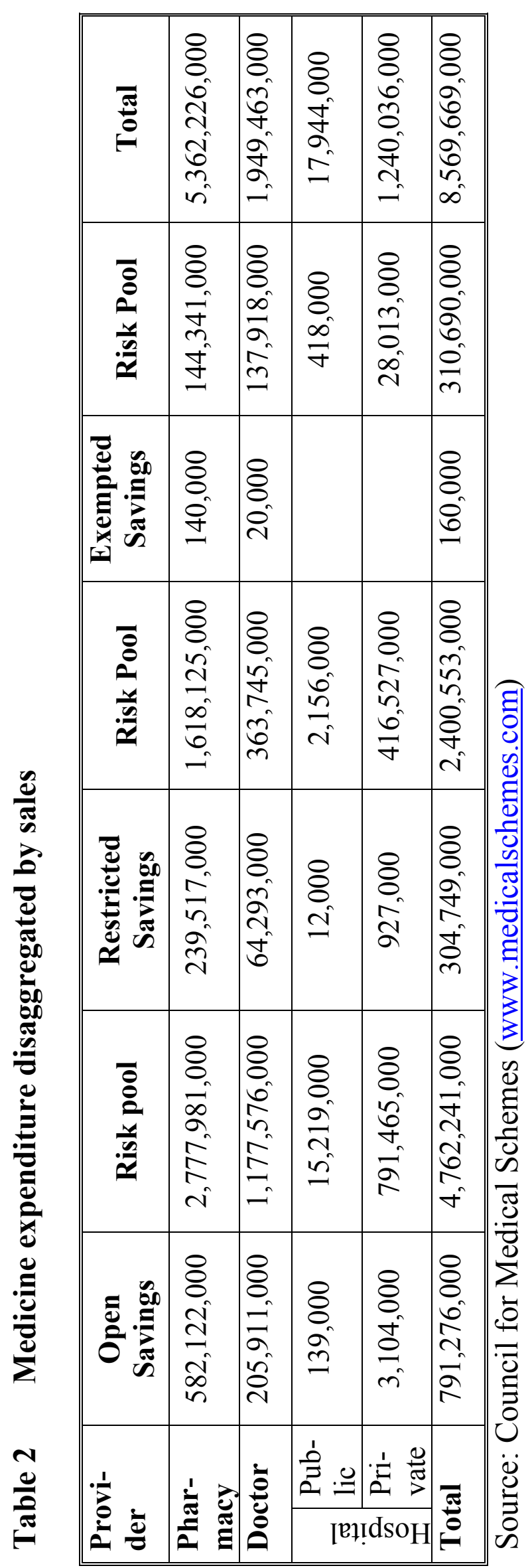




\subsection{Shortage of pharmacists}

The world is experiencing a shortage of pharmacists and this has put extreme pressure on South Africa to keep its pharmacists. With first world countries being able to offer lucrative packages many pharmacists have left South Africa with the associated loss of human capital. In the USA there is such a shortage of pharmacists that graduating pharmacists can make roughly $\$ 90,000$ a year in New York. This is attributed to the fact that the number of prescriptions in America is growing by 6.5 percent while the number of pharmacists available in the industry is only increasing by about 1 percent per year. The reason is that the baby boomers are ageing and drug companies are advertising more aggressively. This has lead to a pharmacist gap because American law requires prescriptions to be checked by a pharmacist (Krulwich, 2002).

The increase in the number of pharmacists emigrating is directly related to the number of letters of good standing issued by the South African Pharmacy Council. These letters are required by overseas registration bodies to ascertain the credibility of the candidate. During 2000, Council issued 514 letters of good standing. The number of these letters issued increased by 4 per cent during 1997, by 109 per cent in 1998, and by 86 per cent in 1999 (SAPC Annual Report, 2000: 24).

The government has also been experiencing a critical shortage in the rural areas and in government run institutions. To alleviate this problem, a system of community service was instituted in 2001 whereby all graduating pharmacists were required to do a year's community service before they could become fully registered pharmacists. This has put enormous pressure on the private sector as they have essentially lost one year of newly qualified pharmacists.

\subsection{Generic substitution}

The government's emphasis on making medicines more affordable to the general public has led to much discussion around generic substitution. Generics are often priced at less than a third of the price of the original product. The makers of original products claim this is due to the fact that they have no R\&D expenses to recoup and that the manufacturing standards are not as stringent. The Medicines and Related Substances Control Act of 1965 does not allow generic substitution by the pharmacist unless the prescribing doctor grants permission. This has proved very cumbersome to apply in practice as many medical aids will only reimburse the generic price and thus force the patient to pay the difference. The current legislation is not conducive to reducing the price of medicines where generics do exist. To try and rectify this matter the Medicines and Related Substances Control Amendment Act of 1997 proposes 
that pharmacists be allowed to substitute with generics after consultation with the patient.

Recently Medscheme, which is South Africa's largest medical aid administrator, introduced its own Medicines Price List (MPL), which sets out the generic alternative it will pay for and how much it is prepared to pay. The reason for this is that in countries like the US, Canada and the UK, generic medicines comprise about 40 per cent of the total market while in SA it is only 20 per cent. Medscheme believes the failure to move towards generics is one of the reasons why 30 per cent of medical aid payments go to medicines compared with 12 per cent to 15 per cent in the rest of the world. (Strong-arm tactics bring pain and gain, 2002: 52).

\subsection{Access to higher scheduled drugs}

Pharmacists have requested that the Medicine Control Council change the scheduling of certain medications so that they can treat minor illnesses. The idea is that pharmacists undergo extensive lessons in the diagnosis and treatment of common illnesses. This would mean that the general public could be treated without having to consult a doctor. This would be much more affordable for the public. The medical profession has been against such a move as they see it as a threat to their own livelihood.

\section{FUTURE SCENARIOS OF RETAIL PHARMACY}

This section examines how the different forms of retail pharmacy are likely to deal with the changing, increasingly complex and cost focused marketplace.

\subsection{The large discount pharmacies}

These are the large format pharmacies $\left(700 \mathrm{~m}^{2}\right.$ and larger) whose main emphasis will be selling fast moving consumables at discount prices. Their dispensaries will focus on that sector of the population that is not on medical aid and thus pay cash for their medicines. They will draw people into the store by offering large discounts on medicines and sell fast moving consumables to them at the same time. These stores are very profitable as they generate a high turnover per square meter. The traditional pharmacy, however, relies almost exclusively on their medicines' turnover and has relatively low front shop turnovers. This means that their stock turns are often very low and they therefore have lots of capital tied up in slow moving stock. Also the small retailers have smaller turnovers and therefore do not have the buying power to compete on price. Unfortunately to open a large discount pharmacy requires a sizeable amount of start-up capital 
and more than one store to generate the volume buying required to get better prices to attract consumers.

\section{The traditional stand alone pharmacy}

There seems to be little scope for this type of pharmacy in the future unless they find a particular niche area in which to compete. With the likelihood that medical aid contracts to supply medicines will increasingly move to PPOs, HMOs and postal medicine pharmacies, these pharmacies may find that their access to prescriptions from doctors shrink. Medical aids are also becoming more aggressive in demanding larger discounts which will put pressure on their margins and may make marginal pharmacies unprofitable. In addition, the competition from large discount pharmacies offering big discounts on medicines are also having a negative effect on their businesses. These pharmacies do not have the buying power to compete with the prices offered by the large discount pharmacies. Their traditional advantage of offering accounts is being eroded as people are no longer prepared to pay a huge premium for credit. Those that will survive will need to find or create a niche for themselves. Examples would be pharmacies in strategically placed rural areas where no competition exists or those that offer specialist services such as diabetic care or personalized cosmetic treatment. Another example would be specializing in homeopathic medicines and offering expert advice. Thus traditional pharmacies that want to remain independent and prosper will need to be entrepreneurial to ensure their survival. Another option open to independent pharmacies is to get together and form an independent pharmacy association (IPA). The role of the IPA would be to negotiate with medical aids to secure contracts for these pharmacies and to negotiate with suppliers to provide group discounts which would allow them to be competitive.

\section{Postal service pharmacies}

Postal pharmacies are a new addition to the pharmacy market having only been in existence for about a decade. Nevertheless they have had a dramatic effect on the pharmacy environment. They came into existence by offering medical aids larger discount on chronic medication. They could do this because they did not have the high overheads of traditional pharmacies such as prime rental, expensive shop fittings and did not have to pay overtime to provide extended hours. They could also service the whole country and thus could develop volume on prescribed medicines which allowed them to buy in huge volumes and get very good prices. This concept has been extremely successful but has more recently come under pressure. These postal service companies promised medical aids that they would have a saving in chronic medication which is the largest part of the medical aid bill. Unfortunately postal delivery has led to 
people using more medicine. Traditionally when people collected medicine at the pharmacy they would only return once the medicine was finished. With postal medication consumers do not want to break the cycle for fear that the medication would not arrive when they really need it and thus receive medication even when they have existing stock. Thus chronic medication costs have actually increased and medical aids are becoming aware of this and are now look at pharmacy networks that can still offer them good prices with the advantages of a traditional pharmacy location. The postal companies will have to look for solutions to counteract this problem. Added to this is the fact that postal and courier services are very expensive and this also puts pressure on their margins.

\subsection{The local chain store}

This may be a very good option for those pharmacists that still want to maintain ownership of their pharmacies but who feel they need to be part of a larger organization to give them stronger negotiation skills. This seems to be the route that Pick ' $n$ Pay and now Clicks are following. This means that each store pays a franchise fee and in return they are marketed under one name and the franchiser negotiates better prices and advertises on a national scale. This could be very important if medical aids start signing exclusive contracts with pharmacy groups. The pharmacists thus retain ownership of the pharmacy and this hopefully will lead to higher standards than one would expect from a manager as the owner has full responsibility and interest in the success of the business. These types of pharmacies will probably be opened in key centres in suburbs which will give convenience for people living in the area.

\section{The pharmacy dispensary alongside a doctor's practice}

Over the past decade many doctors have been dispensing medication to supplement their income. This has been a very profitable practice as the pharmaceutical companies often offered them very lucrative deals as an incentive to prescribe their drugs. Added to this, the medical aids discriminated between doctors and pharmacies forcing pharmacies to give larger discounts than the dispensing doctors. This meant that they operated at very high margins. However, as doctors are often very busy consulting patients they did not have the time to effectively administer a pharmacy. Whilst margins were very high, inefficiencies in administration could still be tolerated and profits realized.

In recent years with the government wanting to introduce legislation to create a one-exit price, doctors no longer get discounts as high as they once did. Added to this, the medical aids are moving towards a uniform discount for all providers which has forced dispensing doctors to give bigger discounts. As a result many 
doctors began to find themselves in financial trouble. Pharmacists have been approached to take over the running of their dispensaries. The primary reason is that pharmacists have better claiming technology and administrative skills than the average doctor. Also pharmacists are involved full time in the running of the dispensary to ensure proper control of all the business functions. Often these pharmacies are run with a profit incentive for doctors so as to ensure that their patients are directed to the pharmacy. This is against the Pharmacy Act but this is often overcome with rental agreements related to turnover.

These types of pharmacies can be very profitable as they do not need to carry the large levels of stock that traditional pharmacies do because only the doctors' preferred drugs need to be stocked. This means that these pharmacies can buy higher volumes of these products and that they can increase there stock turn dramatically. While these pharmacies are very successful, they do face the risks of being excluded from medical aid contracts. Nevertheless this pharmacy concept is very practical as it gives great convenience to customers who can see the doctor and receive their medication at the same time. Also for pharmacists that want to open their own pharmacy, this is probably the most cost effective way of entering retail pharmacy.

The large corporates have not missed this opportunity and companies like Medicross have opened doctors' practices that have a pharmacy attached. With their large buying power these dispensaries have become one of Medicross's most profitable areas of business.

\section{CONCLUSION}

We have clearly seen from this study that retail pharmacy is currently going through one of its most challenging times. Huge pressure is being put on pharmacies from the medical aids to reduce the cost of medicines. The retail pharmacy industry is also constantly changing and this is being accelerated by the new proposed legislation that will open up ownership of pharmacies. The big players in the retail market have already made their intentions very clear. The government has a big interest in what form the health care market will take and want to see a more inclusive private healthcare market. All these factors mean that it is unlikely that the future retail pharmacy market is going to resemble the status quo. This paper has outlined the probable changes.

Lastly, whenever there is great change and uncertainty there is also great opportunity. With a good understanding of the latest developments in the healthcare markets entrepreneurial pharmacists can use their skill and expertise to create value in the market place. 


\section{ENDNOTES}

1 This paper is partly based on an MBL dissertation by Martin Wessels.

2 This can be defined as a system that manages the utilization, costs (including the inflation rate) and quality of services to ensure that a defined population receives appropriate, cost effective and high quality healthcare (Chetty 2000: 1).

\section{REFERENCES}

1 CHETTY, M. (2000) Introduction to the Basics of Managed Care in South Africa, Durban: Parke-Davis.

2 COUNCIL FOR MEDICAL SCHEMES (2002) www.medicalschemes. com.

3 FINANCIAL MAIL (2002) Strong Arm Tactics Bring Pain and Gain, $26^{\text {th }}$ July: 52.

4 GRANT, M.R. (1998) Contemporary Strategy Analysis, Blackwell: Oxford.

5 KRULWICH, R. (2002) Prescription for Success, ABC News, $26^{\text {th }}$ April.

6 SUNDAY TIMES (2002) Low Cost Quality Pays Off, $16^{\text {th }}$ June 2002: 6.

7 LUIZ J.M. (1994) "Health care in the new South Africa: Surveying the more radical options", Africa Insight, 24(2): 127-32.

8 LUIZ J.M. \& WESSELS, M. (2003) "Private medical care in a changing healthcare environment in South Africa", forthcoming.

9 MELAMET, DA. (1994) Commission of Enquiry into the Method of Providing for Medical Expenses, Government Printing Office: Pretoria.

10 REEKIE, W.D. (1995) Health-care options for South Africa: Lessons from the UK and the USA, Free Market Foundation: Sandton.

11 REEKIE, W.D. (1997) "Cartels, spontaneous price discrimination and pharmacy retailing", International Journal of the Economics of Business, 4(3): 79-285.

12 SAIRR (South African Institute of Race Relations) (2001) South Africa Survey 2001/2002, Cape Town.

13 SOUTH AFRICAN PHARMACY COUNCIL (2000) Annual Report 2000, Pretoria.

14 UNDP (2001) Human Development Report 2001, United Nations: New York.

15 WOLVAARDT, G. (2002) 'The introduction of a National Health Insurance System - Implications for general practice', GP Net Insight, July No 6: 10-11. 